\title{
Infrastructure Enhancement to Support Value-Added Bioproduct Recovery
}

\author{
Jason S. Gordon', John B. Auel1, Nia Blair-Agyeman², Iris B. Montague², Rubin Shmulsky² \\ ${ }^{1}$ Department of Forestry, Mississippi State University, Starkville, USA \\ ${ }^{2}$ Department of Sustainable Bioproducts, Mississippi State University, Starkville, USA \\ ${ }^{3}$ United States Forest Service, Northern Research Station \& Forest Products Marketing Unit, City, USA \\ Email: jg966@msstate.edu
}

How to cite this paper: Gordon, J.S., Auel, J.B., Blair-Agyeman, N., Montague, I.B. and Shmulsky, R. (2018) Infrastructure Enhancement to Support Value-Added Bioproduct Recovery. Natural Resources, 9, 129-149.

https://doi.org/10.4236/nr.2018.94009

Received: February 27, 2018

Accepted: April 25, 2018

Published: April 28, 2018

Copyright (C) 2018 by authors and Scientific Research Publishing Inc. This work is licensed under the Creative Commons Attribution-NonCommercial International License (CC BY-NC 4.0).

http://creativecommons.org/licenses/by-nc/4.0/

\begin{abstract}
The purpose of this research was to identify and make available new and existing information to facilitate more effective response by individuals, organizations, and government entities when storms and other forms of catastrophic disturbance lead to unplanned influxes of downed timber and woody debris across the southeastern United States. To this end, this project explored attitudes and behaviors of stakeholders regarding their post disaster timber salvage experiences. Findings are reported from twelve focus group sessions with forestry decision makers, including landowners, loggers, foresters, and agency representatives. Data were analyzed using an iterative coding process that organized large quantities of text into fewer categories and identified emergent themes. Relationships between themes and categories were described within and across cases based on their concurrence, antecedents, or consequences. This technique was followed by a content analysis focusing on discovering underlying meanings and understanding explicit versus euphemistic terms. Findings center around economic limitations and opportunities, social networks in resource utilization, and diverse interpretations of the disaster event. As well, findings demonstrate how risk perceptions and disaster experience interact to construct social meanings for disaster and associated preparedness activities. Implications include value-added utilization options for woody storm debris that have been pursued in past storm events and lessons learned that can inform future decisions.
\end{abstract}

\section{Keywords}

Timber Salvage, Disaster, Casualty Loss, Focus Groups, Non-Industrial Forest Landowners 


\section{Introduction}

Forests cover over 65 percent of the southeastern United States and provide important economic, social, and environmental benefits to residents. Extreme weather, such as tornados, hurricanes, and wildfire, poses a significant risk to forest landowners and the ability to achieve their objectives from their forestland. In particular, wind- and wildfire-damaged trees can prevent landowners from realizing full economic benefits of the timber resource. Given emergency managers' prioritization of life and homes, and the confusion of disaster response, among other challenges, salvaging timber can be a difficult task for landowners to undertake following a disaster event. As a result, damaged wood can remain unutilized on the landscape leading to potential wildfires and pest outbreaks in addition to lost revenue. It is therefore critical that state and federal agencies address the challenges of post disaster timber salvage in order to maximize economic, cultural, and environmental benefits from forestland, while minimizing risks from disaster-impacted landscapes.

Two nested objectives drove this research: (1) to identify new and existing information to facilitate more effective response by individuals, organizations, and government entities when storms and other forms of catastrophic disturbance lead to unplanned influxes of downed timber and woody debris across the southeastern United States; and (2) to explore the linkages between risk perceptions, information needs, and disaster response regarding post disaster timber salvage and forest recovery. To address these objectives, we employed a series of focus group discussions with forest landowners, foresters, loggers, and other natural resource professional.

\section{Literature}

Within the human dimensions of natural resources literature, studies on risk perceptions and post disaster response to natural disasters have focused overwhelmingly on wildfire, which is understandable given state and federal budgets dedicated to wildfire risk mitigation and suppression. Risk perceptions and mitigation vary according to geography, past experience with disaster, trust in land management agencies, length of residency, landscape preferences, resource dependency, and mass media accounts of events e.g., [1] [2] [3]. As a result, research explaining why residents do not always follow guidelines offered by risk managers has been inconsistent. For example, the human dimensions of wildfire literature has found previous experience to be a factor in creating defensible space around homes; as well, it has been associated with apathy regarding the perceived likelihood of repeated wildfire events [4]. Similarly, proximity to wildfire has been shown to increase concern [5] [6].

Although some differences have been observed for race and gender, sociodemographic (including geographic) variables by themselves have rarely explained important differences in attitudes and behaviors toward forest disaster events [3] [7]-[12]. This includes residency status (e.g., urban vs. rural and permanent vs. 
seasonal) which has been linked to divergent views in resource management (i.e., prescribed fire, thinning, grazing), but not significant differences in risk perceptions per se [9]. Similarly, educational efforts to draw attention to wildfire risk, such as Fire Wise and similar programs, have shown mixed results [13]. Inconsistencies suggest intervening social, economic, and ecological elements influence the ways individuals and their communities view and address a potential disaster [14] [15].

Some consistencies exist in the literature regarding public information dissemination about forest-impacted disaster events. Public response to information depends on trust and familiarity of the source. This applies to both the source medium (e.g., Internet or radio) and the author [16] [17], with residents typically using a variety of sources. Geography also plays a role in information seeking with urban versus rural and regional differences noted in the literature. Rural residents are more likely to learn about disaster information from radio and newspaper sources than their urban counterparts [18]. Several studies have noted face-to-face interactions with agency personnel regarding land management have a significant effect on accessing and accepting disaster information. For example, Toman et al. [19] found post-fire field tours with the U.S. Forest Service influenced support for fuels treatment and increased confidence in the agency's land management efforts.

While general unidirectional communication may not tend to result in major public response, locally relevant information has influenced locally-specific risk perceptions as well as some preparedness activities [11] [20]. Relevancy is also a function of up-to-date information and how the disaster impacts residents' daily lives (e.g., effects to their home and evacuation). Real-time information helps provide a sense of control and lessen anxiety [11]. According to McCaffrey [4], residents seek information about disaster location, evacuation information, and available services such as shelters at the start of the event. If residents have evacuated, they want to know about how the event has impacted their homes and communities. Once the event has passed, residents seek information about when to return home, health and safety risks, and availability of services, insurance, debris disposal, and rebuilding assistance. Thus, communication of information must occur before, during, and after the event.

In comparison to the research focusing on wildfire preparedness and response, timber salvage studies have been largely approached from biological or economic perspectives e.g., [21] [22] [23]. Their research has resulted in, for example, standardized techniques for assessing damage and change in growth rates, disease, stain, decay, and insect damage probabilities, remedial stand treatments, economic decision support tools. In a unique study that examined relationships between timber salvage and risk perception, Deng et al. [24] addressed landowners' willingness to purchase standing timber insurance using a contingent valuation approach. The study focused on individual tradeoffs between perceived economic risks to forestland investment versus premium costs; 
however, the scope of the article did not address the various noneconomic values involved in forest landownership and risk response. By comparison, a limited number of noneconomic approaches have focused primarily on public conflict over salvage logging in National Forests [25] [26] [27]. Such studies involve a completely different context in terms of ownership structure, management goals, and decision-making processes than salvaging timber on nonindustrial private forest lands.

At the core of the risk and disaster literature is the degree of objectivity in risk assessment [28]. At one extreme are technical risk perspectives which assume risk can be objectively quantified-risk exists "out there independent of our minds and cultures, waiting to be measured" ([29], p. 119). At the other extreme are cultural theories emphasizing the subjectivity of risk [28]. Cultural theories suggest risk is socially constructed through social and political processes resulting in heightened vulnerabilities. Themes found in the risk literature illuminate how risk is created and distributed, individuals' awareness of and reaction to risk, and factors influencing how people think about risk [30].

For example, an engineering approach might seek to measure the objective risk that a flood levee will not fail during an "average" Category 5 hurricane. Cultural theory proposes that risk did not exist until people created the opportunity for a disaster to occur through, for example, land use change and human settlement in the flood zone [31]. Despite their differences, both perspectives associate risk with the uncertain loss of something valuable to humans. In the case of forestland risks, timber is not the only potential loss; additional loss may be related to, for example, a disruption of sense of place, interruption of recreational activity, and psychological distress. Acknowledgment of non-timber losses is important when considering strategies for conveying disaster response information and, ultimately, increasing landowners' resilience.

In addition to activities before, during, and after the event, risk management involves multiple levels of socio-political organization. Actions include zoning, insurance, public education, fuel reduction, warning systems, emergency plans, and post disaster relief. An additional option, in some cases, is to do nothing. As suggested by Foster and Orwig [32], there is little long-standing biogeochemical disruption following hurricane impacts and insect infestation; thus, from an ecosystem perspective, disturbances are important natural features providing habitat and landscape heterogeneity leading to ecosystem resilience. Nevertheless, managers must also consider social resilience, including financial consideration, human safety, and risks such as wildfire and pathogen outbreaks that could result from landscape scale forest disturbance. The landowner's capacity to salvage his timber before blue stain fungus sets in is an indicator of resilience, both at the individual and community levels [30]. When properly designed and implemented, risk management leads to resilience while acknowledging the unique cultures and contexts found across communities and sociodemographic groups. 
In short, responses to disaster depend on if and how residents interpret risk. Risk perception research has indicated individuals and groups interpret risks differently based on evaluations of losses and gains, cultural biases, and socioeconomic factors used to judge uncertainties. This research sought to identify information needed by stakeholders to facilitate decision making, effective networking, and efficient resource utilization following a major forest disturbance. Towards this end, we explored the intersection of information needs, risk perceptions, risk mitigation, and disaster response.

\section{Methods}

\subsection{Site Selection}

To explore and better understand disaster response focus groups were employed across the Southeastern United States. Focus group locations selected based on discussions with natural resource leaders, such as state forestry agency supervisors, and geographic proximity to large numbers of forest landowners. A third criterion for selection was prior experience with natural disasters.

Sessions were located in: Eastern Texas (Beaumont), Louisiana (Alexandria), Mississippi (Purvis, McComb, Jackson), Alabama (Mobile, Fairhope), Florida (Chipley), Georgia (Ludowici), South Carolina (Florence), North Carolina (Bolivia), and Virginia (Suffolk). According to the National Woodland Owner Survey (NWOS), the nine study states contained over 112 million acres of family forestland with at least 10 acres having about two million owners during the survey period 2011 to 2013 [33]. Passing the land to heirs is the primary important objective for most landowners. Twenty-six percent of family forestland had been harvested for sale; however, only 14 percent had a forest management plan. As well, the NWOS reports about 24 percent of landowners received advice from a public or private forestry professional, whereas seven percent received advice from another landowner or family member. About a quarter of surveyed landowners preferred to receive advice from the Internet compared with 66 percent who preferred face-to-face interaction. Finally, the NWOS reports the most common concern among landowners was property taxes (73 percent) and keeping the land intact for future generations (72 percent).

\subsection{Data Collection}

Focus groups were conducted between February 2016 and June 2017. Initial contacts were identified by project team members using organizational websites (e.g., state forestry agency). These contacts were asked for additional contacts to recruit for sessions. Each session attempted to include: 1) individual landowners; 2) private forestry professionals; 3) state resource management agencies; 4) cooperative Extension personnel; 5) loggers; and 6) state forestry association representatives. Sessions were conducted in public places with at least six participants per session (with the exception of Virginia).

Sessions lasted between one and two hours with open-ended questions ad- 
dressing: 1) prior experience with natural disasters (not having prior experience did not disqualify a participant from the session); 2) degree of trust in forestry professionals, including public and private foresters; 3) knowledge of available resources; 4) experiences with timber salvage following a disaster; 5) awareness and interest in timber insurance; and 6) suggestions for online information using the website, Wind Wood Utilization (http://www.windwoodutilization.org/) ${ }^{1}$, as a reference. In addition, probes were asked as new issues and information emerged. A sign-in sheet gathered sociodemographic background information.

Table 1 and Table 2 indicate participant characteristics. In total, the project included 86 participants across the 12 focus group sessions. The average age of

Table 1. Number of participants per state $(\mathrm{N}=86)$.

\begin{tabular}{ccc}
\hline State & $\mathrm{n}$ & $\%$ \\
\hline Alabama & 10 & 12 \\
Florida & 7 & 8 \\
Louisiana & 6 & 7 \\
Mississippi & 23 & 27 \\
North Carolina & 7 & 8 \\
South Carolina & 12 & 14 \\
Texas & 9 & 10 \\
Virginia & 3 & 4 \\
Georgia & 9 & 10
\end{tabular}

Table 2. Participant Characteristics $(\mathrm{N}=86)$.

\begin{tabular}{lcc}
\hline Demographics & $\mathrm{n}$ & $\%$ \\
\hline Average age & 56 & 65 \\
Male & 74 & 86 \\
Female & 12 & 14 \\
White & 86 & 100 \\
\hline Occupation & 10 & 12 \\
Extension agent & 19 & 22 \\
Private forester & 28 & 32 \\
Landowner & 9 & 10 \\
Logger & 6 & 7 \\
State forestry association & 11 & 13 \\
State forestry service & 2 & 2 \\
Federal resource manager & 1 & 1 \\
Other & &
\end{tabular}

${ }^{1}$ United States Forest Service sponsored the Wind Wood Utilization website 
participants was 56 years. The majority were male ( 74 or 86 percent) and all participants were white ( 86 or 100 percent). Repeated attempts to recruit non-white participants to focus groups were unsuccessful. Loggers were also difficult to recruit, which was not unexpected as one of the project directors has considerable experience working with loggers. Regardless of the low number of loggers (nine), project personnel believe sufficient information from loggers was captured when aggregated across sites.

As Berg [34] noted, focus groups are not intended to statistically represent the study population, but are an appropriate technique in situations where highly efficient collection of exploratory data is necessary. Morgan [35] pointed out that the size and number of focus groups vary depending on factors such as data saturation, the amount of information each participant contributes to the group, research objectives, and the detail required by the researchers. Session attendance ranged from three to twelve participants (landowners and professional foresters were represented in each session), an ideal size to facilitate spontaneity and exchange among participants, enable participants to consider their own views in the context of the views of others, and moderate the level of facilitator involvement [35] [36] [37]. The focus group methodology used here reflects decades of similar designs utilized in social science, health care, and marketing research (e.g., [35] [37] for comprehensive reviews).

\subsection{Analysis}

Sessions were audio-recorded to complement facilitator notes. Transcriptions were analyzed for emergent themes using a two-step coding process involving reading through the transcripts and then coding into thematic categories while interpreting line-by-line [38]. Themes were compared within and across cases with trends and key differences presented in this article using quotes as illustration. Internal validity was addressed by the coauthors individually analyzing the data. Three additional researchers, including a graduate student, who attended several sessions also reviewed the analysis, thereby contributing to internal validity. If these reviewers disagreed with interpretation of the findings, or if anything was omitted that should have been included, the analysis was discussed and revised as appropriate [35] [38]. Results are presented using illustrative quotes.

\section{Results}

Results are organized by four prominent emergent themes: 1) disaster and salvage experience; 2) market conditions; 3 ) disaster information preferences; and 4) resilient actions.

\subsection{Disaster and Salvage Experience}

To provide a minimal but structured framework for discussion, facilitators informed participants that the sessions addressed a range of forest related distur- 
bances. Participants along the Gulf Coast focused on storm events, while Atlantic coast participants tended to focus on wildfire, and Virginia participants were concerned about ice storms. In all cases, specific catastrophic events held a prominent place in participants' memories, which steered discussions towards that type of disaster (also see [39]). Events discussed to a lesser extent included feral pig damage, drought, pine beetle infestation, flooding, and non-catastrophic wind storms.

Although every participant had a unique story to tell, they exhibited shared memories such as the chaotic period following the event, how people were taken advantage of in their time of need, and how neighbors pulled together to provide support. These quotes illustrate the theme of group experience.

This group has a master's degree in dealing with natural disasters. (landowner, Texas).

It was a real revelation of what happened over night and the next morning we woke up to something we just couldn't believe when looking at it, it was just terrible. (landowner, Mississippi)

Participants expressed awe and acknowledged the power of natural forces: "They [trees] were all facing one way to the south; which was interesting because when I came through [fleeing the storm], they were all facing to the north" (landowner, Mississippi). They discussed the chaos of having to deal with countless post disaster problems, many of them more immediate and lifethreatening than timber salvage, with home damage as the first priority. When they finally had time to address their timber casualty loss, they recalled anxieties related to the process of salvaging. One landowner was intensively involved in the salvage operations on his property following Hurricane Katrina. He noted the dangerous post disaster conditions of his forest.

There is more people hurt, more morbidity, more illnesses, more injuries that occur after the storm from people that messed with [fallen trees], than there is during the storm. If it doesn't look safe, then it's not safe. Don't mess with it-get some help. Don't operate that piece of equipment you've never played with before. You already made it through the disaster, don't hurt yourself trying to recover from it. (landowner, Mississippi)

The two quotes below illustrate the challenges of salvaging material when confusion and stress run throughout the community during a post disaster situation.

I don't like nothing about [salvaging]! I don't like salvaging timber, everybody is upset. It doesn't matter whether you are buying it from them or selling it to someone, everyone is upset.... (landowner, Texas)

Realize that after a disaster, peoples' habits change... [like] the time they [go to] sleep.... See everything changes.... I'll give you a beautiful example of how friends turn out not to be friends. (landowner, Mississippi) 
Many landowners and foresters described negative experiences with loggers following a disaster: “ $\ldots$ if you're not watching loggers, there is a percentage of them that will slip some loads past you and away from you that you are not going to get paid for" (landowner, Alabama). As well, several sessions discussed the difference between outside loggers versus local businesses, which likely increases the confusion between parties: "And a lot of the people [loggers that come in after a storm] are not local people at all. They come in from all sorts of places." Referring to a hurricane, a logger in Mississippi summed up the post disaster salvage situation.

Logger: I saw a lot of things really done wrong. Loggers taking advantage of people and they shouldn't have. Saw a lot of things done right too, but it really is a mess after a storm. Something that big at that size, it's really a bad deal....

Facilitator: Could you explain that-'took advantage of folks?

Logger: Prices. People were just at the mercy of the loggers, and were charging a lot more than what they really needed to. And a lot of [landowners] didn't know any difference.

Despite having experienced several catastrophic events, most participants expected future events.

It is not a matter of if, it is a matter of when it is going to occur. (forester, Alabama)

People have these short memories. I have already lived two life times. I lived through Camille and Katrina and those are once in a lifetime storms supposedly. (forester, Mississippi)

They hoped their experiences would make them more prepared for the next event: "In our experience we learned some lessons, too" (landowner, Mississippi). Participants' negative experiences with the disasters contrasted starkly with their determination to continue living and enjoying their forest in risk-prone places.

\subsection{Timber Markets}

Negative salvaging experiences must be considered in the context of timber markets, a prominent theme during discussions, with subthemes addressing excessive post disaster wood volumes, market prices, parcel sizes, and timber insurance. For instance, professionals (foresters, timber buyers, and loggers) lamented the abnormal volumes of salvage material after storm disasters, particularly large scale events. Most admitted local markets would not sustain similar mega-storm events.

I'd say probably with [Hurricane] Fredrick we got $50 \%$ of [the timber] salvaged, and that is just a complete guess right off the top of my head. Ivan and Katrina, I'm saying we probably got about $30 \%$ to $40 \%$ of it. If we had 
[another disaster] now I'd say we would be lucky to get up to $10 \%$. It has no place to go. (mill manager, Alabama)

Oversupply was partly a function of mill shortage, a result of ongoing changes in the forest products sector and the 2007-2009 housing bubble burst. Participants reported salvage events quickly overwhelmed the relatively few mills and logging companies remaining: "The lack of markets has driven loggers out of business" (logger, Mississippi). The next quote underscored concerns about market conditions that negatively impacted salvage situations, and the associated reduction of the logging force over the last decade.

I have heard a lot of depressing stuff here today; that's the one reason I hated to come because there is nothing good to talk about. I mean we are just holding on by a thread. If it wasn't for my real-estate business, I would have shut down last year. (logger, Mississippi)

Professionals noted that additional demand, resulting from storm damage, would not increase availability of loggers and mills. Further, they described salvaged material as lower quality than non-damaged timber, resulting in low prices from mills.

Landowners had noticed the shortage of loggers following a storm: "That is something that everybody is talking about, being able to find loggers," said a Tex as landowner. Unlike professionals, however, landowners tended to associate difficulty in hiring a logger with forest parcel size. Landowner participants-who tended to own less than one hundred acres-expressed feelings of being marginalized because they were told they lacked the wood volume needed to contract a logger for salvage. It appears that after major disturbances, to some degree, loggers make the economically rational choices to work on larger tracts and pursue production economies of scale. Landowner participants believed large-acreage landowners had some kind of pre-determined access to loggers and mills that was unavailable to smaller-acreage owners due to intermittent harvests.

What I have seen are the big guys, with the big tracts, with the big contracts, their stuff is going to go to that mill, but the little guy gets left out. I guess that's just nature. The big lions kill more than the little ones.... I was way down here on the totem pole. (landowner, Mississippi)

The quote illustrates a common thread of fatalism emerging from many of the small-parcel landowners in the sessions. Low timber prices exacerbated the issue. A landowner from Georgia commented: "Current prices are low, so folks are not harvesting like they used to.... I know the markets are terrible, but there ought to be a niche for the small landowners." Participants agreed that many landowners were less likely to manage their timber for any objective during depressed market conditions. Consequently, a salvage situation was unlikely to be immediately addressed, if at all, because owners have little economic incentive while the activity requires considerable effort. 
Loggers noted that even landowners with over fifty acres had difficulty salvaging their timber if they did not have existing relationships with procurement foresters and loggers. One forester indicated he would not consider working with new landowners until all of his established clients had been assisted: "You [ask yourself] what can I do to accommodate the people I normally do business with? And that is what you do [first]" (Florida). A forester in Georgia agreed and further suggested having a consultant was insufficient unless that consultant had a good working relationship with a logger. "Unless you have a consultant that has a relationship with people [loggers], you are going to be in trouble."

To address the economics of timber salvage, participants were asked about their attitudes towards timber insurance. Other than the Georgia participants, landowners generally seemed to be aware of timber insurance. However, regardless of experience with casualty loss, they did not see insurance as a beneficial investment based on ownership size: "The profit margins are too narrow. For me I can't buy insurance like that" (landowner, Florida). One landowner suggested landowners should have access to government subsidies similar to farm insurance programs.

\subsection{Disaster Information Preferences}

Most participants reported their support for an Internet information portal. However, after briefly reviewing the Wind Wood Utilization website, almost all participants noted the difficulty in finding immediately relevant information for their specific situations. Further, the majority of participants said they would appreciate disaster information at a localized level rather than the statewide or national level information presented on the website. This quote that sums up the general attitude among all participants: "I want to know what is going on county-wise" (landowner, Mississippi).

Participants emphasized that becoming aware of information after a disaster was of limited use; rather, options and opportunities should be made aware to stakeholders prior to the disaster. A landowner in Texas said: "this is a good idea for people to utilize before a storm just get to know what [organizations and agencies] do and what they offer before the storm comes." Participants suggested individuals who normally find day-to-day information regarding their property management on certain websites or visiting local assistance offices will return to those information sources when they need help. According to participants, awareness of salvage information should be initiated at frequently used sources such as school websites and community social media sites. Participants also mentioned the need for disaster response information regarding local goods, services, tips, and announcements not related to timber salvage because these topics were of immediate concern following a disaster. These suggestions underscore the importance of linking salvage information to topics immediately relevant to stakeholders' daily lives. Another landowner in Mississippi stated:

[Landowners need] a place where [we] can go online, and they can tell you 
when the federal people are going to be setting up in this building and taking applications, that is what I need to know, and there is going to have a water giveaway, and the distribution point will be here, they are going to have MRE's [Meals Ready to Eat] here, or they're going to open this senior citizen home here, or emergency gas that is going to be available here.... [Or] You can use the same site for when they are going to give away trees for Arbor Day, along with when they are going to distribute diesel during a disaster.

While age was a negligible factor in accessing the Internet, limited access to utilities in rural counties and electrical disruption were major limitations.

Time sensitivity of information posted to the website was a recurring theme among participants as well: "Every link needs to be checked very frequently and often because they come and go all the time" (forester, South Carolina). Participants noted that forest industry is dynamic-markets change, mills close, new mills may have material requirements that cannot be fulfilled by using salvage material. Another participant implied that this should really be tied to social media and not rely on the static website as much: "A dynamic website has got to be there because that is the whole purpose of the social media is to get them to go there" (landowner, Alabama).

In addition to these suggestions, participants discussed trust in information resources. While some participants had sought advice from county extension agents or local state forestry agencies, participants from Texas to Virginia were unlikely to trust federal government resources. This was unsurprising given the sessions took place in a geographic area known for support for government decentralization. However, this lack of trust was also related to past experiences, both in pre and post disaster contexts, as well as natural resource and other agencies (the Federal Emergency Management Agency and Internal Revenue Service, in particular). Focus group comments indicated that many federal agencies were lumped together in a post disaster situation. The following statement from an Alabama forester broadly illustrates attitudes towards federal government assistance.

The programs in my experience are so unresponsive to getting the money when you need it. They will give you money to plant trees, but the money comes over in August [not when you need it for planting].

Underscoring the need for local input, comments such as these suggest planning and design for information dissemination should consider alternatives to top-down approaches. Participants suggested local resources, agencies, and officials may be able to develop a more effective line of communication with those who need it following a disaster than non-local players. It should be noted that participants did not advocate discontinuation of federal government programs; rather, they were unsatisfied with certain aspects of existing programs. 


\subsection{Resilient Actions}

Any analysis on risk perceptions and vulnerability must account for attitudes and behaviors leading to resilience. Within and across cases, participants interwove expressions of frustration and desperation with stories of individual and collective agency. Three prominent themes regarding local resilience were relationships with professionals, peer networks, and self-sufficiency.

Participants suggested strong relationships were critical to salvaging disaster-damaged timber. Often, professionals will first take care of a client who he has worked with in the past. Several landowners commented on the importance of employing a forestry consultant to manage timber over the lifecycle of the stand. These participants said a consultant having contacts with loggers and mill operators is more likely to start salvaging sooner than a landowner without a consultant.

Having contacts is about the only way that you could get it done.... But if you are a private landowner and have no contacts, no consultant, no relationship with a forester you can forget about it these days. (landowner, Virginia)

Another focus group commented that even a forester does not guarantee timber salvage if that forester does not have strong ties with loggers. The Texas focus group discussed at length the benefits of a strong network of "foresters and people you trust to use here" (landowner), underscoring how such a network must be developed before the disaster:

I have heard so many horror stories and sob stories about landowners that are seemingly helpless. That tells me that landowners should align themselves as much as possible with consultants, have a relationship, in the industry on an ongoing basis. If somebody is a good wood supplier and has done a good job [then] keep his card and number handy, you know. If [landowners] had people that they have trusted before, now is the time to call them, not when your timber is all broke and cut up. A big point I would make is that time is of the essence, you know.

Notably, a landowner in Mississippi stated strong pre disaster relationships were not always sufficient: "The other thing you need to be aware of is that people you thought might be able to help you might not recognize your name when you talk to them after a storm." This participant explained that what he considered to be strong relationships before the storm disappeared when his network of foresters and loggers could make more money elsewhere.

In addition to a professional network, focus group participants demonstrated the importance of landowner relationships. In particular, participants in Mississippi and Texas discussed local forest landowner organizations as critical to their success in forest management, particularly regarding knowledge building and planning. Further, these networks were instrumental in communicating information and professional contacts following a storm. In one case, landowners 
discussed a collaborative approach to timber salvage.

[Referencing inability to salvage small parcels] We have talked about banding together, several of us that live close together, and see if we can negotiate a contract through that (landowner, Georgia)

Participants described the importance of such organizations for absentee landowners, a large contingent of forest landowners. In cooperation with professionals, landowner organizations could provide advice and mentoring to those who do not frequently interact with their land. Such social networks were seen as more valuable than published information, which is often unnoticed before the event and is not helpful in the aftermath.

Resiliency materialized collectively and individually. Several participants described how they learned from previous disaster experiences and, in turn, passed this knowledge to other landowners. A Mississippi landowner had developed a manual for post disaster response:

First of all, know what you got on your property before the storm. You got to have an inventory-and a good one. Also, keep good records, keep good receipts, dates, times, what you did, what you spent, and what it was for. If you're a property owner, you need yourself a management plan, and I think you need a disaster preparedness [plan], or a disaster response module with that plan.

The quote demonstrates a comprehensive view of forest management related to storm damage. It also illustrates risk assessment and contingency planning for destructive events and circumstances that may be very rare. Despite the physical and psychological impacts of their disaster experiences, and despite the potential for future events, participants expressed a profound attachment to their land and communities, and felt a responsibility to care for the resources on their property. The following quote from a Texas landowner illustrates.

I never run from a hurricane. I should have, but I didn't because I just couldn't leave my land. I had five gallon buckets all across the house, the water would come down and fill the buckets. We knew that we were going to be without water. And as far back as we were we were going to have to cut [the trees] ourselves out. We couldn't leave because of our animals, and the next day when getting out of the house, our dogs would walk up to the buckets and wouldn't touch the water [salt water].

This stubborn refusal to evacuate was present in all focus groups. Such comments suggest a rational acceptance of risk, knowledge of sheltering in place, a sense of responsibility regarding property, and a connectedness to place. Leaving would result in a disruption to well-being that would outweigh the risks associated with sheltering in place. It is important to acknowledge that the landowner associated with the quote above was not immune from the effects of the disaster. She also said, "When I saw my place I went ahead and cried, I didn't have 
anything else to do but just bawl." Together, these quotes demonstrate both an emotional and cogent resolve to stay with one's land, which cannot be overlooked when designing disaster response strategies. Expecting such landowners to consume and process scattered information from the Internet or printed sources may not result in the outcomes intended by information specialists.

\section{Discussion}

Several factors emerging from this analysis were related to risk perceptions and collective interpretations of disaster memory. For example, reflecting previous research, people do not always follow guidelines offered by risk managers [39]. Risk perceptions and mitigation behaviors reflect a complex web of contextual influences, with economic tradeoffs potentially acting as a fairly limited aspect of decision-making [24] [28] [29]. The risk may not be salient in the antecedent conditions of residents who, while understanding that a catastrophic event is likely, may do little to mitigate the potential consequences. Campaigns to provide risk mitigation information, including information on timber insurance services, should tailor efforts to reflect the interplay of social, cultural, and physical factors if residents' everyday lives [12] [20] [40]. A practical aspect of this approach would be to link timber salvage information with non-salvage topics addressing pre-disaster mitigation and disaster response [41]. This would include forestry activities (e.g., thinning as a risk mitigation activity and salvage as a response activity) as well as first response, such as building an emergency kit, filling the car with gas, and continue listening to weather radio after the disaster.

Further, the federal government's definition of disaster may not align with definitions of the citizens who experienced the event. In this study, participants indicated that a catastrophic disaster was only a capstone to the ongoing disaster of timber prices. In addition to negative experiences during the disaster, depressed markets caused anxiety and deterred many landowners from engaging in forest management (also see [31]). As a result, stakeholders may not be drawn to timber salvage information, especially prior to the disaster when the information matters most. Scale of information dissemination also matters in how to address risk and disaster. The disaster literature consistently views the impacts of disasters as localized and event-specific; thus, risk and response information should be downscaled rather than generalized [42]. Because disaster concerns varied by region, a regularly updated information portal would emphasize local (as defined by state authorities) concerns and needs over a nation-wide or South-wide approach. For example, the web site might be divided into sections for the Gulf Coast (windstorms) and Atlantic Coast (wildfire and ice damage).

Place attachment, landowners' profound attachment to their land and communities, was associated with resilience, particularly in the form of self-sufficient individuals who would prefer to shelter in place rather than flee their property. This finding reflects similar findings focusing on place-based resilience [42]. In many cases, local knowledge and planning emerged as strengths that an infor- 
mation portal should encourage [43] [44]. Acknowledging the resourcefulness of landowners may also inspire landowners to learn more about post disaster timber management and ongoing risk mitigation activities. Distributing information to absentee landowners, who may have different attitudes towards their land than residents, may require a unique approach to be effective.

Attempting to contract loggers to salvage timber was a major source of anxiety for participants. In some cases, the challenge of contracting loggers deterred landowners from salvaging their timber and from pursuing forest management activities. Results suggest information sources should integrate knowledge resources with guidelines and incentives. Strategies should consider educating landowners and loggers about what to expect after a disaster, customer service, casualty loss, contracting loggers, and other topics. As well, a mechanism should be considered that facilitates contracting logger services after a disaster within a local area in order to exploit economies of scale. This may take the form of, for example, an online resource or disaster aid open-house.

A lack of understanding about logging operations, and sharing pre- and post disaster information, suggests the need to strengthen local social networks. Social networks have been shown to be a primary factor in vulnerability and resilience [45]. A structure could be developed to facilitate interaction among landowners and between landowners and professionals. For example, landowner associations could be initiated and/or strengthened. This would also encourage peer-to-peer networking and sharing of information. Despite the Internet, research suggests one of the best ways of creating awareness continues to be word of mouth [46]. However, combined with social media efforts, such as Facebook and Twitter, Internet-based information on landowner groups and activities could be broadcast to a diverse landowner audience. Moreover, greater interaction among stakeholders could increase opportunities to build successful relationships between professionals and landowners which, according to the findings, were critical to salvaging timber (also see [47]). Improved interactions could lead to understanding and empathy regarding post disaster experiences, including the multiple roles loggers play in disaster clean-up. In addition, strengthened social networks could provide opportunities to form management groups to exploit economies of scale for salvaging and hiring foresters for ongoing management activities of small parcels (this is being implemented in group certification schemes).

Some of the most important findings suggest the excessive supply of wood following a disaster is a critical limitation to post disaster timber management. Coupled with the economics of small parcel sizes, perceptions were worsened by depressed timber prices, which often led to landowners exiting from forest management activities altogether. Research and policy are needed to develop new markets and strengthen existing markets for post disaster wood. To this end, an information portal could supply some of the data needed to encourage entrepreneurship and collaboration. The portal could also provide information 
about timber insurance. Subsidized timber insurance, similar to crop insurance, might incentivize more landowners to purchase the service. In short, web-based information should be coupled with economic development so that landowners and professionals can increase their economic resilience to disasters.

Participants provided several suggestions for an improved information portal. First, they noted the need for an easy-to-navigate, regularly updated web site as essential for repeated visitation. Real-time information was important, as was off-line material because post disaster circumstances often involve electrical outage [11]. Such off-line material should synthesize the most important information, such as how to contact the local government agency offices, into materials such as a trifold brochure, refrigerator magnet, or pocket-sized quick reference guide. Incorporating social media could be an efficient strategy for involving local authorities in the dissemination of real-time web site information. These findings highlight the need for web site developers to work with state and local actors.

\section{Conclusions}

Results suggest four broad dimensions of timber salvage response represented by various possibilities of combinations. First, professional relationships emerged as a critical dimension of successful timber salvage activities, and were influenced by government response, self-sufficiency, and parcel size. Second, disaster experience, or memory of the disaster, was influenced primarily by government response, experiences with loggers, risk perceptions, self-sufficiency, and pre-disaster information. Two additional factors-social memory [31] and popular media [29] — could also have been important influences, however these did not emerge strongly from the focus group data.

Third, vulnerabilities emerging from the data included lack of pre-disaster information, depressed pre-disaster timber markets, industry changes and volatility (linked to markets), lack of knowledge about forestry, compromised forest health, and a weak connection to some groups of local forest landowners (e.g., absentee landowners). Fourth, relationships with fellow landowners were associated with individual and collective agency-key aspects of resilience. A strong social network and shared pre-disaster information contributed to building capacities.

Engagement with forest landowners, loggers, foresters, and their communities is essential if a significant improvement in harvesting disaster-damaged timber, and reducing associated risks, is to be achieved. Conveying information through a web site is one activity; however, efforts should also focus on local capacity-building, including utilizing knowledgeable landowners and existing social networks. The findings suggest policies and practices to increase landowners' and communities' economic opportunities, while reducing negative impacts, would likely increase support for timber salvage as well as forest management more broadly. 
Future research is needed to further define, measure, and generalize findings. Such a survey should be regional and consider the salience of disasters by scale, frequency, impact, disaster type, and recency. Social network analysis would provide in-depth description of social relationships of communication and, therefore, improved ways of providing pre- and post-disaster assistance. As well, research is needed to develop new markets, strengthen existing markets, and explore logistic efficiencies for post-disaster wood. This work would examine storage and reloading of recovered material, as well as spatial distribution of forest products manufacturers relative to raw material supply. Third, research is needed regarding landowners' motivations for purchasing timber insurance as well as innovative insurance tools that appeal to customers [24]. An Internet information portal could provide insurance information to stakeholders. Finally, research is need that addresses urban and rural-urban interface areas. Post disaster issues include debris removal (and utilization), tree risk management, and storm water management related to lost tree canopy. Urban tree risks often persist years after the disaster event risking residents' health and creating liability for cities.

\section{Acknowledgements}

This research was funded by a grant from the United States Forest Service, Northern Research Station \& Forest Products Marketing Unit

\section{References}

[1] Beebe, G.S. and Omi, P.N. (1993) Wildland Burning: The Perception of Risk. Journal of Forestry, 91, 19-24.

[2] Shindler, B.A. (2000) Landscape-Level Management: It's All about Context. Journal of Forestry, 98, 10-14.

[3] Nelson, K.C., Monroe, M.C. and Johnson, J.F. (2005) The Look of the Land: Homeowner Landscape Management and Wildfire Preparedness in Minnesota and Florida. Society and Natural Resources, 18, 321-336.

https://doi.org/10.1080/08941920590915233

[4] McCaffrey, S. (2015) Community Wildfire Preparedness: A Global State-of-theKnowledge Summary of Social Science Research. Current Forestry Reports, 1, 81-90. https://doi.org/10.1007/s40725-015-0015-7

[5] Manfredo, M.J., Fishbein, M., Haas, G.E. and Watson, A.E. (1990) Attitudes towards Prescribed Fire Policies. Journal of Forestry, 88, 19-23.

[6] Vining, J. and Merrick, M.S. (2008) The Influence of Proximity to a National Forest on Emotions and Fire-Management Decisions. Environmental Management, 41, 155-167. https://doi.org/10.1007/s00267-007-9041-y

[7] Bowker, J.M., Lim, S., Cordell, H.K., Green, G.T., Rideout-Hanzak, S. and Johnson, C.Y. (2008) Wildland Fire, Risk, and Recovery: Results of a National Survey with Regional and Racial Perspectives. Journal of Forestry, 106, 268-276.

[8] Ryan, R.L. and Wamsley, M.B. (2008) Public Perceptions of Wildfire Risk and Forest Management in the Central Pine Barrens of Long Island (USA). The Australasian Journal of Disaster and Trauma Studies, 2008, 2. 
[9] Shindler, B.A., Toman, E. and McCaffrey, S.M. (2009) Public Perspectives of Fire, Fuels, and the Forest Service in the Great Lakes Region: A Survey of Citizens-Agency Communication and Trust. International Journal of Wildland Fire, 18, 157-164. https://doi.org/10.1071/WF07135

[10] Gordon, J.S., Stedman, R.C., Matarrita-Cascante, D. and Luloff, A.E. (2010) Wildfire Perception and Community Change. Rural Sociology, 75, 455-477. https://doi.org/10.1111/j.1549-0831.2010.00021.x

[11] McCaffrey, S., Toman, E., Stidham, M. and Shindler, B. (2013) Social Science Research Findings Related to Wildfire Management: An Overview of Recent Findings and Future Research Needs. International Journal of Wildland Fire, 22, 15-24. https://doi.org/10.1071/WF11115

[12] Toman, E., Stidham, M., McCaffrey, S. and Shindler, B. (2013) Social Science at the Wildland-Urban Interface: A Compendium of Research Results to Create Fire-Adapted Communities. U.S. Department of Agriculture, Forest Service, Northern Research Station, Newtown Square, PA.

[13] McCaffrey, S.M. and Olsen, C.S. (2012) Research Perspectives on the Public and Fire Management: A Synthesis of Current Social Science on Eight Essential Questions. U.S. Department of Agriculture, Forest Service, Northern Research Station, Newtown Square, PA.

[14] Carroll, M.S., Cohn, P.J., Seeholtz, D.N. and Higgins, L.L. (2005) Fire as a Galvanizing and Fragmenting Influence on Communities: The Case of the Rodeo-Chediski Fire. Society and Natural Resources, 18, 301-320. https://doi.org/10.1080/08941920590915224

[15] Blanchard, B. and Ryan, R.L. (2007) Managing the Wildland-Urban Interface in the Northeast: Perceptions of Fire Risk and Hazard. Northern Journal of Applied Forestry, 24, 203-208.

[16] Winter, P. and Cvetkovich, G.T. (2010) Trust Mediates Conservation-Related Behaviors. Ecopsychology, 2, 211-219. https://doi.org/10.1089/eco.2010.0046

[17] Steelman, T.A., McCaffrey, S.M., Velez, A.K. and Briefel, J.A. (2015) What Information Do People Use, Trust, and Find Useful during a Disaster? Evidence from Five Large Wildfires. Natural Hazards, 76, 615-634. https://doi.org/10.1007/s11069-014-1512-x

[18] Ryan, B. (2013) Information Seeking in a Flood. Disaster Prevention and Management, 22, 229-242. https://doi.org/10.1108/DPM-05-2012-0059

[19] Toman, E.L., Shindler, B., Absher, J. and McCaffrey, S. (2008) Postfire Communications: The Influence of Site Visits on Local Support. Journal of Forestry, 106, 25-30.

[20] Brenkert-Smith, H. (2010) Building Bridges to Fight Fire: The Role of Informal Social Interactions in Six Colorado Wildland-Urban Interface Communities. International Journal of Wildland Fire, 19, 689-697. https://doi.org/10.1071/WF09063

[21] Sun, C. (2016) Timber Market Recovery after a Hurricane. Forest Science, 62, 600-612. https://doi.org/10.5849/forsci.15-123

[22] Prestemon, J.P., Abt, K.L., Potter, K.M. and Koch, F.H. (2013) An Economic Assessment of Mountain Pine Beetle Timber Salvage in the West. Western Journal of Applied Forestry, 28, 143-153. https://doi.org/10.5849/wjaf.12-032

[23] DiGirolomo, M.F., Allen, D.C., Stehman, S.V., Stout, S.L. and Wiedenbeck, J. (2013) Insect Damage to Wind-Thrown and Standing Live Black Cherry Resulting from Delayed Salvage after a Major Abiotic Disturbance. Northern Journal of Applied Forestry, 30, 101-108. https://doi.org/10.5849/njaf.12-032 
[24] Deng, Y., Munn, I.A., Coble, K. and Yao, H. (2015) Willingness to Pay for Potential Standing Timber Insurance. Journal of Agricultural and Applied Economics, 47, 510-538. https://doi.org/10.1017/aae.2015.23

[25] Manning, R., Valliere, W. and Minteer, B. (1999) Values, Ethics, and Attitudes toward National Forest Management: An Empirical Study. Society and Natural Resources, 12, 421-436. https://doi.org/10.1080/089419299279515

[26] Bengston, D.N. and Fan, D.P. (1999) Conflict over Natural Resource Management: A Social Indicator Based on Analysis of Online News Media Text. Society and Natural Resources, 12, 493-500.

[27] Manring, N.J. (2004) Locking the Back Door: The Implications of Eliminating Postdecisional Appeals in National Forest Planning. Society and Natural Resources, 17, 235-245. https://doi.org/10.1080/08941920490270285

[28] Douglas, M. and Wildavsky, A. (1982) Risk and Culture. University of California Press, Sacramento, CA.

[29] Slovic, P. (1992) Social, Cultural, and Psychological Paradigm. In: Krimsky, S. and Golding, D., Eds., Social Theories of Risk, Praeger, Westport, CT, 117-152.

[30] Tierney, K.J. (1999) Toward a Critical Sociology of Risk. Sociological Forum, 14, 215-242.

[31] Wisner, B., Blaikie, P.T., Cannon, I. and Davis, I. (2004) At Risk: Natural Hazards, People's Vulnerability, and Disasters. Routledge, London.

[32] Foster, D.R. and Orwig, D.A. (2006) Preemptive and Salvage Harvesting of New England Forests: When Doing Nothing Is a Viable Alternative. Conservation Biology, 20, 959-970. https://doi.org/10.1111/j.1523-1739.2006.00495.x

[33] Butler, B.J., Miles, P.D. and Hansen, M.H. (2017) National Woodland Owner Survey Table Web-Application Version 1.0. U.S. Department of Agriculture, Forest Service, Northern Research Station, Amherst, MA.

http://fiatools.fs.fed.us/NWOS/tablemaker.jsp]sessionid=4B67B3508BC661AA68A1 $\underline{416 \mathrm{~A} 952330 \mathrm{BC}}$

[34] Berg, B.L. (2004) Qualitative Research Methods for the Social Sciences. 5th Edition, Pearson, Allyn \& Bacon, Boston.

[35] Morgan, D.L. (1996) Focus Groups. Annual Review of Sociology, 22, 129-152. https://doi.org/10.1146/annurev.soc.22.1.129

[36] Patton, M.Q. (1990) Qualitative Evaluation and Research Methods. 2nd Edition, Sage, Newbury Park, CA.

[37] Morgan, D.L. (1997) Focus Groups as Qualitative Research. 2nd Edition. Sage, Thousand Oaks, CA.

[38] Creswell, J.W. (1998) Qualitative Inquiry and Research Design: Choosing among Five Traditions. Sage, Thousand Oaks, CA.

[39] Fischer, A.P. and Charnley, S. (2012) Risk and Cooperation: Managing Hazardous Fuel in Mixed Ownership Landscapes. Environmental Management, 49, 1192-1207. https://doi.org/10.1007/s00267-012-9848-z

[40] McCaffrey, S. (2015) Community Wildfire Preparedness: A Global State-of-theKnowledge Summary of Social Science Research. Current Forestry Reports, 1, 81-90. https://doi.org/10.1007/s40725-015-0015-7

[41] Tierney, K. and Bruneau, M. (2007) Conceptualizing and Measuring Resilience: A Key to Disaster Loss Reduction. TR News May-June 2007, 14-17.

[42] Cutter, S.L., Barnes, L., Berry, M., Burton, C., Evans, E., Tate, E. and Webb, J. (2008) A Place-Based Model for Understanding Community Resilience to Natural Disasters. 
Global Environmental Change, 18, 596-606.

https://doi.org/10.1016/j.gloenvcha.2008.07.013

[43] Tew, R.D., Straka, T.J. and Cushing, T.L. (2013) The Enduring Fundamental Framework of Forest Resource Management Planning. Natural Resources, 4, 423-434. https://doi.org/10.4236/nr.2013.46052

[44] Paveglio, T., Prato, T., Dalenberg, D. and Venn, T. (2014) Understanding Evacuation Preferences and Wildfire Mitigations among Northwest Montana Residents. International Journal of Wildland Fire, 23, 435-444. https://doi.org/10.1071/WF13057

[45] Cutter, S.L. (1996) Vulnerability to Environmental Hazards. Progress in Human Geography, 20, 529-539. https://doi.org/10.1177/030913259602000407

[46] Vanderford, E., Gordon, J.S., Londo, A.J. and Munn, I. (2014) Using Focus Groups to Assess Educational Programming Needs in Forestry. Journal of Extension, 52, 3FEA9. https://www.joe.org/joe/2014june/a9.php

[47] Useche, P. (2013) Collective Action in Common Pool Resource Management, including Heterogeneity of Opportunities and Exit Options. Natural Resources, 4, 483-489. https://doi.org/10.4236/nr.2013.48059 